\title{
Turbantes e bonecas Abayomi: estratégias para o fortalecimento da etinicidade afro- brasileira em espaços educativos ${ }^{1}$
}

\author{
Bruna de Paula Pereira² \\ Maria Alice Rezende Gonçalves ${ }^{3}$
}

\begin{abstract}
Resumo
Este artigo tem como objetivo descrever as ações educativas desenvolvidas por uma blogueira e ativista negra, visando o fortalecimento da etnicidade afro-brasileira em espaços escolares, com oficinas de turbantes e bonecas realizadas em uma escola em Mesquita/RJ. Conclui-se que o ativismo digital possui um potencial educativo na medida em que possibilita a difusão da informação sobre as questões ligadas à valorização e ao fortalecimento da identidade negra, bem como a extensão dessas ações no espaço presencial escolar. Isso contribui para o estreitamento dos laços entre a escola e a comunidade no processo de implementação da lei n 10.639/03.
\end{abstract}

\author{
Palavras-chave \\ Ativismo digital; Educação antirracista; Turbantes; Bonecas; Etnicidade.
}

Turbants and Abayomi dolls: strategies to strengthen afro-brazilian ethnicity in educational spaces

\begin{abstract}
This article aims to describe the education actions developed by black activist bloggers aiming to strengthen Afro-Brazilian ethnicity in school spaces, with the turbans and dolls workshops held at a school in Mesquita/RJ. It can be concluded that digital activism has an educational potential as it enables the dissemination of information about issues related to the valorization and strengthening of black identity, as well as it allows the extension of these actions in the classroom environment. Thus, contributing to the strengthening of ties between the school and the community in the process of implementing Law 10.639/03.
\end{abstract}

Keywords

Digital activism; Anti-racist education; Turbans; Dolls. Ethnicity.

Artigo recebido: novembro de 2020

Artigo aprovado: dezembro de 2020 


\section{Introdução}

Este artigo tem como objetivo descrever as ações, desenvolvidas por uma educadora, blogueira ativista negra, visando o fortalecimento da etnicidade afro-brasileira em espaços escolares, como oficinas de turbantes e bonecas realizadas em uma escola do município de Mesquita no estado Rio de Janeiro entre os anos de 2015 e 2016. A diversidade cultural e étnico-racial da sociedade brasileira é afirmada na Constituição de 1988. Gonçalves e Silva (2000) afirmam que, nessa época, o debate sobre a educação dos negros teve maior repercussão devido ao Centenário da Abolição prosseguindo nos anos seguintes. Na primeira década do século XXI, entram, na agenda governamental, as políticas de reconhecimento da diversidade étnica no país. Essas são medidas importantes, como a implantação da lei ${ }^{\circ}$ 10.639/03, que altera a Lei de Diretrizes e Bases da Educação Brasileira (LDB, n 9.394/96), tornando a história e a cultura afro-brasileira e africana obrigatórias nos currículos escolares do ensino básico e as políticas de inclusão de negros no ensino superior. Oliveira (2013) atribui ao movimento negro à proposição da lei e, avaliando seu período de implementação, conclui haver ainda muito a ser feito nesse sentido, no entanto destaca a existência de trabalhos exitosos sendo desenvolvidos e que deveriam ser amplamente divulgados. Acrescenta que a lei $n^{\circ}$ 10.639/03 é para todos, sendo preciso pensar estratégias e políticas públicas que garantam sua concretização, tanto no espaço universitário, quanto na educação básica. Gomes (2003) destaca, ainda, a importância das ações dos movimentos negros em conjunto com as instituições de ensino. Para a autora, as escolas que percebem a importância do trabalho coordenado com a comunidade, dos movimentos sociais e profissionais negros que lidam no seu cotidiano com a questão racial, abrem as suas portas para um trabalho compartilhado. Consideramos, nesta investigação, que as ações compartilhadas devem estar verdadeiramente comprometidas com a eliminação do racismo e a valorização da cultura afro-brasi- 
leira. Nesta investigação apontamos para a especificidade das ações educativas oriundas dos espaços virtuais e se integram ao ambiente escolar caracterizando a emergência de um "novo ativismo" e de "novos sujeitos" que alimentam a relação de ensino aprendizagem na escola. Além da incorporação das políticas da diversidade pelo sistema de ensino, destaca-se, no início de século XXI, o avanço das novas tecnologias da comunicação e da informação, que introduzem novas ferramentas para a participação política e difusão da agenda e mobilizações dos movimentos sociais. Consideramos como pressuposto que, nesse contexto de inovações tecnológicas, surgem novos tipos sociais no cenário virtual e no ativismo negro brasileiro, como as blogueiras ativistas negras. A partir do surgimento de novas formas de ativismo e de novas identidades, nos interessa descrever as ações educativas presenciais oriundas do ambiente virtual, desenvolvidas por uma educadora, blogueira e ativista negra em uma escola de um município localizado na periferia da cidade do Rio de Janeiro.

Neste artigo, a cidade do Rio de Janeiro é entendida como um dos polos irradiadores de novas etnicidades para o país, notadamente, a que diz respeito à cultura popular negra. As políticas da diversidade, a intensificação dos fluxos migratórios principalmente advindos do sul global e o contato, virtual ou não, com as culturas diaspóricas retiraram a cidade da posição de cidade periférica e a transformaram em polo irradiador pluricultural e pluriétnico para todo o país. Alimentando, assim, o surgimento de novos comportamentos e provocando mudanças visíveis nos modos de vida, nos saberes e fazeres racializados, como o estilo "afro", aqui representado, pelo uso dos turbantes e na feitura de bonecas negras. As blogueiras e ativistas negras sensíveis às novas formas de viver a negritude introduzem na esfera da militância uma forma particular de fazer política baseada em ações virtuais e presenciais criando ferramentais digitais, organizando eventos presenciais onde o tema central é a discussão de questões relativas ao mundo negro assumindo, assim, o lugar de um dos agentes repro- 
dutores dessa nova cultura popular negra. Por meio da permanente conexão com outros grupos da mesma natureza, seja no ambiente virtual, seja no presencial, elas criam redes que se estendem para além da cidade circulando por outros estados da federação.

A cultura negra contemporânea não é e nem nunca foi produzida unicamente no continente africano, elas são frutos das negociações com a cultura eurocêntrica e com as demais culturas humanas. Para Hall (2003) a cultura negra, marginalizada em relação ao mainstream, nunca foi um espaço tão produtivo quanto agora. O autor identifica um "novo tipo de política cultural" resultado de lutas em torno da diferença validas para diferentes grupos étnicos, feminismos ou movimentos LCBTQI+. No entanto, identifica haver, concomitantemente, um movimento de resistência à diferença. Pensando a relação entre a escola e a cultura popular negra contemporânea, supomos que a tentativa de manutenção dos currículos escolares eurocentrados é um bom exemplo dessa resistência. Esse fato, certamente pode explicar a morosidade no processo de implementação da lei 10639/03 nas escolas brasileiras apesar dos esforços de alguns docentes e de ativistas do movimento negro.

Ao refletir sobre as redes sociais como ferramentas para articulações de membros de movimentos sociais, Castells (2013) destaca que as redes sociais digitais oferecem a possibilidade de deliberar sobre e coordenar as ações de forma amplamente desimpedida. O mesmo autor define comunicação como o processo de compartilhar significado pela troca de informações. Para ele, a influência das redes sociais nas mobilizações urbanas pode ser exemplificada com a mobilização que ficou conhecida como Primavera Árabe, que eclodiu a partir de dezembro de 2011, no Oriente Médio e Norte da África. No final de 2010, o jovem Khaled Saeed foi torturado até a morte pela polícia egípcia, o irmão do jovem tirou uma foto da câmera do celular do cadáver deformado no necrotério e postou na internet, o que gerou uma grande comoção. O executivo do Google no Egito, Whael Chonim, criou uma 
página no Facebook chamada: “Somos todos Khaled Saeed”, onde divulgou as fotos do corpo deformado pela tortura. Chonim publicou em sua página e no blog convites para que os egípcios marchassem no dia 25 de janeiro de 2011. No protesto os manifestantes levavam cartazes com a foto de Saeed morto. Essa manifestação contou com 15 mil pessoas e desencadeou uma série de protestos no mundo árabe que ocasionou a queda do ditador Hosni Mubarak depois de 30 anos de regime militar. As reflexões de Castells (2013) nos auxiliam a pensar tanto as novas tecnologias da informação e comunicação e a formação de redes, quanto os "novos" movimentos sociais e o ativismo digital.

Para Gohn (2011), o diálogo entre os movimentos sociais nos espaços educativos pode ser considerado ativismo, pois aqueles podem intervir no processo de aprendizagem para a transmissão desses saberes. Os participantes dos movimentos sociais também produzem coletivamente e transmitem saberes entre si. Gohn ressalta que (2011, p. 334): "os movimentos tiveram papel educativo para os sujeitos que o compunham." Supomos que os "novos" movimentos sociais digitais, além de poder ser caracterizado pelo uso das ferramentas digitais, podem ser identificados como sendo de dois tipos, os que eclodem a partir de um evento e aqueles que se formam a partir da experiência pessoal do ativista. O primeiro caso foi exemplificado por Castells (2013).

evento da morte do jovem torturado e morto pela polícia egípcia detonou uma série de protestos após a postagem de fotos na internet.O segundo tipo tem como elemento mobilizador a experiência pessoal da blogueira negra. Elas são jovens negras que a partir de suas vivências e do uso de ferramentas digitais, como os blogs, atuam em prol da difusão da cultura negra e da valorização da estética negra. Consideramos que às ações e práticas educativas do ativismo negro digital realizado por meio das ações das blogueiras negras guardam especificidades. Elas atuam nos campos da construção positiva da identidade negra; do fortalecimento do pertencimento ao grupo étnico e da etnicidade negra somando a isso o acesso às novas tecnologias. Nas oficinas atu- 
am em campos de interesse para a mobilização e conscientização da questão racial, como a educação, a estética, a moda, a valorização da identidade negra, a participação política, o combate ao racismo, o fortalecimento do associativismo negro, entre outros.

Como definir as fronteiras entre os afro-brasileiros e os outros? Barth (1976, p. 189) conceitua grupo étnico como aquele que: "perpetua-se biologicamente de modo amplo; compartilha de valores culturais fundamentais, realizados em patente unidade nas formas culturais; constitui um campo de comunicação e de interação; possui um grupo de membros que se identifica e é identificado por outros como se constituísse uma categoria diferençável de outras categorias do mesmo tipo". O autor ressalta que os grupos étnicos são vistos como uma forma de organização social, na medida em que atores usam identidades étnicas para categorizar a si mesmo e aos outros, com objetivos de interação, formando grupos étnicos no sentido organizacional. Ainda de acordo com o mesmo autor, esses grupos estabelecem fronteiras através de seus marcadores que, apesar da interação e relação com outros grupos, são capazes de definir quem pertence ou não ao grupo étnico. Segundo esse conceito, entende-se que os afro-brasileiros criam estratégias para organização e manutenção de uma coesão grupal. Além da concepção de Barth (1976), de grupo étnico, utilizamos o conceito de "comunidade étnica” de Weber (1991). Para ele, a crença em uma origem comum faz com que grupos de pessoas construam uma base capaz de formar uma comunidade, independentemente da existência de um parentesco sanguíneo. A partir desses referenciais, consideramos que os afro-brasileiros poderiam ser entendidos como uma comunidade unida na esfera política por uma situação em comum, ou seja, a busca por direitos à cidadania. Seyferth (2011) fornece pistas para pensar como afro-brasileiros constroem e reconstroem sua coesão por meio da etnicidade, estimulando, assim, o sentimento de pertencimento étnico. A mesma autora (SEYFERTH, 2011) nos fornece pistas para pensar como afro-brasileiros constroem e reconstroem 
sua coesão por meio da etnicidade estimulando, assim, o sentimento de pertencimento étnico. Para a autora, de acordo com a Fenton (apud SEYFERTH, 2008, p. 3) etnicidade diz respeito à descendência e à cultura, se refere à construção social da descendência e da cultura. Acrescenta, ainda, que os grupos étnicos elaboram estratégias para fundamentar costumes e sentimento de pertença comum: "Povos não possuem apenas culturas ou ancestralidade compartilhada, eles elaboram as duas coisas para compor uma ideia de ancestralidade que cerca as definições de grupos ou comunidades, procura mostrar que os rótulos étnicos (ou outras categorias) não estão no vazio, têm uma base real a sustentá-los" (SEYFERTH, 2011, p. 50).

Como turbantes e bonecas podem fortalecer a etnicidade de um grupo étnico? Para Gonçalves (2011), o fenômeno da etnicidade tem um significado social, pois está mais ligado ao sentimento, à cultura, à socialização, ao interesse de um grupo étnico do que a um conceito de raça. Podemos considerar, então, que a identidade étnica é um fenômeno grupal e está relacionada à construção da identidade do indivíduo. Quanto mais forte é a etnicidade, mais coeso e consolidado será o grupo. O conceito de etnicidade, então, permite-nos pensar como as ações educativas, oficinas de turbantes e bonecas, propostas pelas blogueiras ativistas negras podem fortalecer a etnicidade afro-brasileira.

A lei 10.639/03 estabelece que somente os profissionais da educação podem ser responsáveis por ministrarem seus conteúdos excluindo os ativistas como um dos possíveis responsáveis pelo processo apesar de alguns serem detentores do repertório sobre a história e a cultura afro-brasileira e africana. Por isso, os ativistas passam a participar da implementação da lei a convite das instituições de ensino propondo atividades presenciais como palestras, ofıcinas, conferências ou rodas de conversa. As oficinas acabam por unir dois espaços, o virtual e o presencial, politizando, por exemplo, o uso dos turbantes e a feitura de bonecas negras; apresentando-os como elementos da 
cultura negra altiva e positiva. Assim, é atribuído a esses itens culturais um significado étnico que serve, de um lado, como ativador da autoestima positiva da criança negra e de outro como forma de difusão da cultura negra apresentando a nação como multicultural.

Na primeira década do século XXI, o cabelo ressurge como um símbolo da etnicidade negra. Elas orientavam o passo a posso de como obter um cabelo "natural", recomendam o comércio e a indústria de cosméticos e beleza que lançam produtos adequados aos cabelos crespos. Houve, também, nesse período, um aumento significativo da literatura com corte racial e um aumento da produção acadêmica sobre a questão racial no país. Para além dos trabalhos sobre as políticas de ação afırmativa notamos o aumento da produção sobre os processos de construção de uma identidade negra por meio do cabelo e de outros símbolos raciais. Rompendo, desse modo, com a descrição simplória do negro como portador de características físicas estereotipadas como: cor da pele escura, cabelo do tipo crespo, narinas largas, os lábios grossos, ainda que um tipo com todas essas características seja raro ou inexistente, e com uma cultura apresentada como "sobrevivências" de algo que tenderia a desaparecer ao ser absorvida pela cultura nacional. Cabe observar que este fenômeno de reforço à cultura negra se intensifica, no início do século XXI, com o advento das políticas da diversidade sem deixar de guardar semelhanças como o movimento "Black is beautiful" dos anos 1960/70. Autores como bell hooks (2005) abordam e descrevem o ritual do alisamento dos cabelos crespos realizado pela mulher negra interpretado como um esforço da negra em parecer branca. Assim, a positivação da autoestima dos negros passa pela assunção dos cabelos crespos. $\mathrm{Na}$ recente produção das ciências humanas e sociais citamos a pesquisa de Comes, tese de doutorado defendida em 2002, onde o cabelo, elemento do corpo, não só biológico, mas também social, é apresentado como um dos símbolos de resistência cultural, uma forma de expressão estética e identitária negra. Figueiredo (2002) alerta para o 
significado dado ao cabelo no que diz respeito à identidade, consumo e aparência dos negros identificando o movimento de ressignificação de estereótipos anteriormente vistos como negativos associados aos fenótipos negros. Os temas, como cabelos crespos, turbantes, trançados de cabelos e outros itens que se vinculam ao corpo e a estética negra foram inspiração para outras investigações como a moda e o lúdico como turbantes ligados a moda afro e as bonecas negras que atendem a carência de brinquedos para a criança negra. Pereira (2016) ao pesquisar os turbantes e bonecas artesanais observa que, as oficinas são uma das ferramentas educativas propostas pelo ativismo digital. A comunicação e a interação entre as blogueiras negras podem inspirar ações que cheguem até o ambiente escolar, mesmo que a blogueira não seja uma profissional da educação.

Essas ofıcinas tiveram como objetivo construir estratégias para uma educação antirracista por meio da apresentação de traços da cultura afro-brasileira para todos os alunos, contribuindo assim, para a implementação da lei $n^{\circ}$ 10.639/03. Na pesquisa apresentada neste artigo, foi dedicado espaço a atividades pontuais, como as ofıcinas realizadas por uma ativista, com objetivo de valorizar e estimular o sentimento de pertencimento entre os afro-brasileiros no espaço escolar. Barth (1976) descreve que a importância fundamental de compartilhar de uma mesma cultura é mais um resultado do que uma característica primordial da organização de um grupo étnico. As ações do movimento negro são significativas não somente na esfera de geração de políticas de inclusão de negros no sistema de ensino, como também para a valorização cultural afro-brasileira. A presença do movimento negro na escola também abre espaço para que os saberes construídos no ambiente virtual sejam transmitidos para os discentes.

Cabe mencionar que o texto da lei $n^{\circ} 10.639 / 03$ refere-se à categoria cor/raça como "afro-brasileiro (a)(s)", enquanto o movimento negro e seus ativistas digitais optam pela categoria "negro(a)(s)", que representa aqueles brasileiros que se autodeclaram pretos e pardos para o 
Instituto Brasileiro de Geografia e Estatística (IBCE). Neste artigo, compreendemos afro-brasileiros e/ou negros como mesmo grupo étnico. No que diz respeito às orientações em direção às diretrizes curriculares nacionais, o documento apresenta um novo campo na educação nacional, a “Educação para as Relações Étnico-Raciais” (BRASIL, 2013). Os impasses teóricos que envolvem os limites dos conceitos de raça e etnia foram superados por meio da noção étnico-racial que agrega as duas perspectivas. Além disso, e de outras providências, a lei torna obrigatório o ensino da cultura afro-brasileira.

Para coleta de dados nas redes sociais sobre as ações e propósitos das ativistas negras, foi utilizada a busca de entrevistas postadas nos blogs e chats. Diferente das pesquisas de campo presenciais, essa metodologia não torna necessário o deslocamento do pesquisador para um espaço físico, o que pode ser desafiador, no sentido de que é preciso uma atenção redobrada para perceber as dinâmicas do campo. Observamos, por meio das postagens em plataformas digitais, como blogs e redes sociais, as atividades que essas ativistas estão desenvolvendo no campo educacional. Segundo Tafarello (2014), a busca de dados no ambiente virtual serve para observar as relações na internet através dos chats, comunidades e redes sociais. As conversas são analisadas pela troca de frases e palavras entre os usuários. Rifiotis (2016) considera o espaço virtual como um actante importante no trabalho do pesquisador: "a pesquisa no campo da cibercultura terá muito a ganhar, levando em consideração a teoria ator-rede"4 A internet pode ser usada como um meio de agrupar pessoas para mobilização presencial - ou seja, fora dela - e pode também ser um espaço onde a mobilização é construída por ações no próprio ambiente virtual. O espaço virtual possibilita às pessoas participarem de discussões sobre questões sociais e raciais e promoverem ações políticas, seja por meio da divulgação de pautas, publicações de reflexões acerca dos movimentos ou por articulações com outros atores envolvidos com uma causa em comum. Esse ativismo pode ser levado para outros es- 
paços ou não. Nesta pesquisa, identificamos como blogueiras negras ativistas, além de usarem o espaço da internet como um meio de propagarem suas mensagens de ativismo ligado à temática antirracista, também se organizam coletivamente em ações presenciais.

Dentro do universo de blogueiras e ativistas negras das redes sociais, há intersecção de raça e gênero. Pode-se observar que as mulheres negras representam uma maioria significativa no atual cenário do ativismo afro-brasileiro na web. Após o I Encontro de Beleza Negra, no YouTube, promovido pelo Afrogooglers ${ }^{5}$ (2015), a blogueira negra, Naomi Ceneroso, no seu blog The Black Cupcake ${ }^{6}$, comenta o fato de haver a predominância feminina no ativismo virtual e conclui que: embora a maioria das pessoas que publica conteúdo no YouTube seja de mulheres, são os homens que têm maiores visualizações. Além disso, as mulheres negras possuem menor visibilidade do que as youtubers ${ }^{7}$ brancas. A blogueira negra supõe que causas advindas do machismo e do racismo podem contribuir para decidir quem terá ou não mais visibilidade.

Consideramos a cultura negra como impura e híbrida. Como as demais culturas ela mantém continuidades e dialoga com as demais culturas, no entanto ela mantém suas especificidades que a tornam única. Mesmo sendo atravessada pelas intersecções de raça, classe de outros marcadores da diferença. Para nós, as oficinas de turbantes e bonecas artesanais têm significados particulares se entendermos em que contexto esses itens são considerados relevantes para a construção da identidade e para a autoestima das crianças negras. A decisão, tomada pela blogueira, de etnografar a própria prática educativa implicou no reconhecimento de três pontos que interferiram nas conclusões da pesquisa: O primeiro refere-se a não essencialização da identidade negra da blogueira. Segundo Hall (2003) as identidades na pós-modernidade são múltiplas. As várias identidades da blogueira, educadora, blogueira, negra ativista, pesquisadora entre outras, são constructos que apontam para a multiplicidade de identidades assumidas pela ativista onde sua experiência pessoal de negra surge como o motivador do ativismo, 
caracterizando, desse modo, um novo modo de fazer política além de estabelecer laços identitários com as crianças negras. O segundo refere-se às relações simétricas estabelecidas entre o universo virtual e o presencial. A blogueira negra propõe uma metodologia que conecta os dois universos, o virtual e o presencial, por meio de oficinas oferecidas nas escolas. E o terceiro diz respeito ao papel de pesquisadora. Ao estabelecer uma relação dinâmica com o grupo pesquisado desenvolvendo uma empatia com as crianças negras e as demais crianças não-brancas, a pesquisadora cria laços afetivos com a escola, com a equipe pedagógica, com os pais e com todas as crianças. Essa relação alimenta e estimula outras intervenções nas escolas.

A conexão entre os ambientes virtual e presencial atribui ao trabaIho da blogueira e educadora uma dimensão específica para além da relação escola e comunidade. A experiência vivida fomenta relações educativas. As experiências nesses dois ambientes, virtual e presencial, aliado ao compromisso ativista em prol da igualdade racial orientou a decisão da pesquisadora em aceitar o convite de execução do trabaIho voluntário nessa escola da rede pública. Cabe, ainda, destacar que o diálogo entre o ambiente virtual e o presencial, em geral pensados como separados, surge modificando as relações de ensino-aprendizagem e construindo novas formas de ativismo negro nos espaços educativos. Podemos afırmar que as blogueiras negras criaram metodologias pedagógicas para a reprodução da cultura negra na escola.

\section{Ações Educativas na Escola Ubuntu: conectando o digital com o presencial e fortalecendo etnicidade.}

Na Escola Ubuntu ${ }^{8}$, nos propomos contribuir com o processo de implementação da lei $n^{\circ} 10.639 / 03$ por meio de oficinas, oferecidas à uma das turmas da escola, que apresentaram dois símbolos da etnicidade afro-brasileira emergentes na cidade do Rio de Janeiro na segunda década do século XXI: os turbantes e bonecas Abayomi. As ofıcinas descritas neste artigo são entendidas como ferramentas para 
o fortalecimento da etnicidade afro-brasileira no espaço escolar, foram realizadas fora do ambiente virtual pelas participantes dos grupos e blogueiras. O experimento foi realizado em uma escola localizada no município de Mesquita-RJ, sobre a qual descreveremos a motivação, a justificativa e os efeitos da Oficina de Turbantes e Bonecas Abayomi, dada por uma educadora e ativista digital de forma presencial, aos alunos do primeiro segmento do ensino fundamental da referida escola. Esse experimento é um bom exemplo da passagem do ativismo digital às ações educativas presenciais.

Com a divulgação dos eventos e reuniões de mulheres negras - cujo foco dos encontros era a valorização do cabelo crespo e cacheado surge o primeiro convite para levarmos as ideias do evento Encrespa Geral (2013) - focado na cultura e estética afro-brasileira e criado por conteudistas das redes sociais - para a Escola Paraíso9 ${ }^{9}$, de Niterói-RJ. As primeiras atividades tinham um formato de palestra ou roda de diálogos, tendo como título: "Crespo é lindo", em que eram expostas mensagens sobre valorização do cabelo crespo com a proposta de desconstruir a ideia do cabelo ruim ou cabelo duro. Após as primeiras experiências, percebemos a necessidade de uma ferramenta concreta, que não fosse apenas atrativa, mas também um facilitador para estabelecer um debate sobre racismo. Assim, optamos pela realização de uma oficina, uma maneira para se estabelecer um debate sobre diversas temáticas por meio de alguma atividade prática. Já havíamos trabalhado com oficinas de bonecas Abayomi, confeccionadas com nós e amarrações, cujo corpo é feito de tecido preto. Nos encontros de mulheres negras e em canais no YouTube, também aprendemos a fazer amarrações de turbantes confeccionados com tecidos coloridos. Tanto as bonecas quanto os turbantes são vistos como pertencentes à estética e à cultura negra.

As oficinas foram ministradas por uma das pesquisadoras, que é moradora no município de Mesquita, não houve dificuldades em conseguir autorização para realizar a pesquisa no espaço, visto que uma docente da instituição a convidou para desenvolver atividades na escola. 
A entrada na escola aconteceu por meio de convites feitos por professores ou coordenadores das escolas para oferecermos oficinas para alunos. A maioria das escolas justifica o convite argumentando sobre: a implementação da lei n 10.639/03; o combate a alguma situação de racismo entre os alunos; ou a celebração de datas comemorativas, como o Dia da Consciência Negra, em 20 de novembro. Quando os convites surgiam, oferecemos as oficinas gratuitamente e os participantes optavam por atividades sobre bonecas ou turbantes. As oficinas foram desenvolvidas em reuniões de pais, turmas do primeiro e segundo segmento do fundamental, do ensino médio, no ensino superior e em reuniões pedagógicas.

Os turbantes e as bonecas Abayomi são usados como um símbolo étnico para referenciar de forma positiva a identidade afro-brasileira. O turbante é usado como um marcador de valorização da estética negra, sendo este frequentemente comparado a uma "coroa" pelas blogueiras negras ativistas. As bonecas Abayomi são vistas como um recurso lúdico que faz frente à ausência de bonecas negras no mercado e é um facilitador para dialogar sobre identidade. Descrevemos, assim, as estratégias que estão sendo utilizadas por ativistas digitais negros para fortalecerem etnicidade afro-brasileira. Em um primeiro momento da pesquisa, visando à descrição das ações virtuais das blogueiras, foi usada a netnografia e para a descrição da oficina na escola, optamos pela etnografia. De acordo com André (2005), a etnografia necessita da interação do pesquisador com o objeto de pesquisa, exercendo idas constantes a campo, para que se colete o máximo de informações, a fim de descrever o objeto pesquisado. Para a autora:

[...] o etnógrafo encontra-se, assim, diante de diferentes formas de interpretações da vida, formas de compreensão do senso comum, significados variados atribuídos pelos participantes às suas experiências e vivências e tenta mostrar esses significados múltiplos ao leitor. (ANDRÉ, 2005, p. 16-17). 


\section{Oficinas na Escola Ubuntu}

A Escola Ubuntu está situada no centro do município e atende as modalidades da educação infantil e ensino fundamental. Em 2016, o número total de matrículas é de 436 alunas e alunos, sendo 210 meninos e 226 meninas. Embora no questionário de matrícula conste a autodeclaração racial, nunca foi feito por parte da secretaria um levantamento sobre esses dados. Na instituição funcionam turmas de educação infantil e ensino fundamental I, organizado em oito turmas na parte da manhã e oito na parte da tarde.

O município da Baixada Fluminense tem 168.403 habitantes. A cidade se concentra em área urbana, em cujo centro há uma concentração de comércios, agências bancárias, instituições escolares municipais, estaduais e privadas. O município tem 17 bairros, segundo - IBGE ${ }^{10}$. Somando rede pública e privada, Mesquita conta com 67 escolas de ensino fundamental, 14 de ensino médio e 44 de educação infantil. Em 2015, constituíam a rede com 23 escolas municipais de ensino fundamental e 14 de educação infantil. Da população residente, 62.095 pessoas se autodeclararam brancas, 1.455 amarelas, 80.464 pessoas se consideram pardas e 24.205 pretas. No município, é comum observar a juventude reunida nos espaços públicos, como a Praça João Luiz do Nascimento, conhecida como "Praça da Telemar", onde ocorrem bailes de funk e de hip hop, concentrando um grande grupo de pessoas.

Recebemos o convite para fazer uma oficina de turbantes em dezembro de 2015, por meio da professora Thalita", que conseguiu estabelecer contato conosco por uma amiga. Esta comentou sobre o trabalho que desenvolvíamos nas escolas e teve acesso a essa informação pela divulgação dessas atividades nas redes sociais. Thalita fez contato e demonstrou interesse na oficina de turbantes. Após acertamos tudo, ficou a cargo da educadora comprar os tecidos. Inicialmente, quando o convite foi aceito ainda não havia a intenção de utilizar o desenvolvimento da atividade como objeto etnográfico da pesquisa. 
No dia da oficina, na chegada à escola, fomos recepcionadas por um funcionário que nos levou até a sala da professora que nos aguardava. Após as apresentações, a professora explicou que só tinha tecidos suficientes para fazer turbantes com as alunas. A oficina foi iniciada com a introdução do livro "Histórias de Preta"12 (PIRES, 1998); as crianças estavam tímidas e a conversa após a leitura do livro teve poucas intervenções. Como não havia espaço para dispor os alunos em círculo, ficamos na frente da turma, ensinando cinco tipos de amarrações. A cada modelo feito, algumas alunas reagiam dizendo: "Eu quero fazer esse!"; “Eu gostei mais desse." Após ensiná-las, colocamos uma cadeira virada para turma e chamamos as alunas (uma por vez) para fazer a amarração desejada, explicando-lhe o passo a passo.

Na sala de aula havia um mural com desenhos de uma mulher negra de turbante, pintado pelos alunos, por conta do Dia da Consciência Negra. As alunas pediram para reproduzir a amarração do desenho, o que não foi possível por conta do tecido de que dispúnhamos não ser tão estruturado. As meninas com cabelos mais crespos demonstraram um receio maior quando tiveram seus cabelos tocados na hora de fazer a amarração do turbante, com comentários negativos sobre o próprio cabelo, como: "Ah tia, esse cabelo!"; “Tia, não sei se a senhora vai conseguir mexer nisso aí." Gomes (2003: 173) afırma que: “o cabelo carrega uma forte marca identitária e, em algumas situações, é visto como marca de inferioridade". Já com os turbantes prontos, as alunas pediam para sair da sala, na intenção de mostrar às funcionárias da escola.

Como pudemos analisar nessa e em outras escolas onde desenvolvemos oficinas de turbantes, por ser comum quando não há condições de distribuir material para todos os alunos, somente as meninas participam da atividade. Isso ocorre mediante a uma escolha arbitrária das professoras, o que nos faz perceber como o turbante é vinculado à estética feminina e como esse acessório vem ao encontro dos estereótipos de gênero. A professora Thalita informou em entrevista que na hora da saída dos alunos, muitos pais pediram para as crianças reti- 
rarem o turbante, alegando ser "coisa de macumbeiro". Relacionamos esse relato com a fala da orientadora pedagógica, ao discorrer sobre a visão dos professores sobre trabalhar a temática racial em sala de aula: "O que bate de frente é a questão da mistura da religiosidade com as heranças [...] com as contribuições do negro no nosso país [...], às vezes as professoras acabam focando mais na questão do não preconceito e da aceitação." A orientadora acredita que os professores não tratam tanto da questão cultural afro-brasileira talvez por receio de enfrentar as resistências advindas da recusa de alguns pais em aceitar a religiosidade de matrizes africanas interpretada com mágica. No Censo do IBGE (2010), 63.580 pessoas se declararam evangélicas no município de Mesquita. A forte presença de alunos de famílias evangélicas também foi uma questão levantada pela orientadora pedagógica.

As manifestações culturais afro-brasileiras, como podem observar nesses relatos da professora e da orientadora, são identificadas como uma só, sem que haja distinção. A intolerância religiosa ligada às doutrinas de matrizes africanas também representa um desafio para o ensino da cultura afro-brasileira na escola. Segundo Gomes (2003, p. 172) "o olhar lançado sobre o negro e sua cultura na escola tanto pode valorizar identidades e diferenças quanto pode estigmatizá-las, discriminá-las, segregá-las e até mesmo negá-las.. Por isso, além das ações pontuais, como as oficinas, é necessário que ocorra uma preocupação de ensinar e valorizar os diversos aspectos culturais afro-brasileiros. Em pesquisa sobre a capoeira no Programa Mais Educação de uma escola do município de Nova Iguaçu-RJ, Pereira constatou que:

Nesse sentido, é possível dizer que a intolerância religiosa se destaca como uma importante variante quando pensamos no diálogo da capoeira com a escola. Como sinaliza a coordenadora do PME, muitas famílias não permitem que seus filhos participem da oficina por entender que a capoeira possui uma ligação com religiões de matriz africana, como candomblé e umbanda (PEREIRA, 2016, p. 77). 
Há um esforço de pesquisadores preocupados em refletir sobre o racismo na escola, propondo debate sobre a temática. Na dissertação intitulada: "Solta o cabelo! etnografía sobre o cabelo crespo como marcador de identidade étnico racial entre crianças negras da educação infantil", Braga descreve como o cabelo crespo é tratado no ambiente da creche por pais, alunos e funcionários. A autora afirma que:

O racismo estruturante provoca um abismo social entre brancos e negros que são fixados ao longo do tempo na vida dos indivíduos. Assim sendo, no campo da educação tem-se a evidência de diferenças entre negros e brancos no acesso e permanência dentro do sistema escolar (BRAGA, 2016, p. 56).

No artigo: "Educação, identidade negra e formação de professores: um olhar sobre o corpo negro e o cabelo crespo", Comes (2003) traz relatos de negras e negros sobre como seus corpos e seus cabelos estabeleciam relações de tensão no espaço escolar, e ressalta que no processo de construção da identidade, o corpo pode ser considerado como um suporte da identidade negra. De acordo com os indicadores do IBCE de 2015, 53,6\% da população brasileira se declara como preta ou parda diferente de 10 anos atrás, quando 51,2\% se autodeclaravam brancos. Podemos considerar que essa maior adesão à categoria "negro" (preto e pardo) se dá em virtude das conquistas de políticas públicas voltadas para esse grupo étnico, como as ações afırmativas no campo da educação. Além da necessidade de articular estratégias de acesso à população negra a educação, as ações voltadas à valorização desse grupo demandam estratégias de permanência desses nos diferentes níveis de ensino.

A letra da música "Falsa Abolição" do grupo Tarja Preta relata uma realidade visível, apesar da maioria da população do país se considerar preta ou parda: "Meninas negras não brincam com bonecas pretas/ Se somos todas iguais por que você me rejeita?". Quantas bonecas negras costumamos ver nas prateleiras das lojas? Existem vídeos no YouTube sobre um experimento ${ }^{13}$ feito com crianças, em que são apresentadas 
a elas duas bonecas, uma branca e outra negra. Em seguida, são feitas perguntas sobre qual das bonecas é a boa, a má, a bonita, a feia, entre outras. Todas as crianças tendem a dar as avaliações positivas para a boneca branca, e negativas para a negra. Pensando em como o racismo se manifesta na infância, até mesmo na escolha dos brinquedos, as oficinas de bonecas Abayomi carregam uma proposta de valorização. A boneca preta que, normalmente, não é escolhida pelas crianças nas brincadeiras, ou sequer tem destaque nas prateleiras das lojas de brinquedos, é a protagonista da atividade. Lena Martins, artesão e difusora da técnica das bonecas Abayomis e criadora da Cooperativa Abayomi localiza o momento de início da confecção e da difusão das bonecas no final dos anos de $1980^{14}$. Consideramos importante citar que hoje é possível encontrar bonecas pretas feitas por outros empreendedores negros, como é o caso da empresa Era Uma Vez o Mundo, que recentemente lançou a primeira loja física do Brasil destinada à venda exclusiva de bonecas e bonecos negros ${ }^{15}$. Os donos da marca são educadores e no site ${ }^{16}$ citam que a missão da marca é: desenvolver espelhos positivos e afırmativos que elevem a autoestima da criança. Os brinquedos e as brincadeiras fazem parte do desenvolvimento da criança. Por meio das brincadeiras se encenam o cotidiano, desenvolvendo a imaginação e a interação social.

Em maio de 2016, retornamos à Escola Ubuntu para desenvolver a Oficina de Bonecas Abayomi com os alunos da professora Thalita, que seguiu com a mesma turma do ano anterior, o que foi favorável para continuidade do desenvolvimento da observação das ofıcinas. Nesse dia, uma amiga nos auxiliou com registros fotográficos e filmagem da atividade. Na chegada à sala de aula, as alunas imediatamente nos reconheceram e correram para nos abraçar, antes mesmo que pudéssemos apresentar a pessoa responsável por fotografar e filmar a atividade. Algumas diziam: "É a tia do turbante!" A professora pediu à turma que se organizasse para irmos ao pátio descoberto, a fım de iniciarmos a ofıcina. Chegando ao pátio, organizamos os alu- 
nos em círculo, apresentamos a nossa "auxiliar" e, também, a boneca preta de cabelos crespos Aisha, personagem importante na oficina. As alunas ficaram agitadas para tocar a boneca, que passou de mão em mão. Iniciamos uma conversa com os alunos, perguntando quem já teve uma boneca parecida com a Aisha. Muitas alunas responderam que sim. Em seguida, perguntamos quem gostaria de fazer uma boneca preta, e explicamos que não seria de pano, costurada, como aquela. Faríamos uma boneca Abayomi.

Terminado esse momento, iniciamos a distribuição do material de confecção. Cada etapa da construção da boneca era explicada, demonstrada e só passávamos para a etapa seguinte quando todas as crianças haviam conseguido completar a parte do processo. Era muito comum, durante a confecção das bonecas, alguma aluna ou aluno solicitar ajuda; mesmo que não tivessem dificuldades. Para ter nossa atenção, perguntavam se estavam fazendo correto ou se era possivel refazer, argumentando que do nosso jeito era mais bonito. Por várias vezes, explicamos para o grupo que as bonecas nunca saem uma igual a outra e isso fazia com que elas nos representassem, afinal, nós também fazíamos parte de um grupo diverso. A acompanhante que havia ido com o objetivo de fazer os registros fotográfıcos da oficina, acabou se envolvendo diretamente no processo, pois as alunas e alunos solicitavam sua ajuda durante a confecção. A professora Thalita participou da oficina no mesmo círculo onde os alunos estavam. Em alguns momentos, intervinha para chamar a atenção do comportamento deles, quando ficavam se levantando muito ou conversando. No entanto, na maior parte do tempo, ela participou ativamente do desenvolvimento da atividade e declarou: "Eu queria muito aprender a fazer essas bonecas!".

Alguns alunos pareciam desconfiados se os tecidos recortados nas primeiras etapas se tornariam de fato bonequinhas. Quando começaram a visualizar as formas, dois meninos da turma perguntaram se eles podiam fazer bonecos, em vez de bonecas. Explicamos que existiam artistas que utilizavam a técnica para fazer personagens femininos ou 
masculinos, e que iríamos ensinar um determinado modelo de Abayomi, questionando se teria problema para eles. Os alunos disseram que não, e seguiram com a confecção. A etapa de vestir as bonecas Abayomi foi a que mais empolgou as crianças. Alguns tecidos de determinadas estampas não estavam disponíveis em grande quantidade e eram disputados pelas crianças. A maioria das meninas utilizou os retalhos cor-de-rosa para vestir suas bonecas. Ao final da confecção, sentamo-nos em roda e a professora perguntou o significado do nome da boneca. Informamos que significava "encontro precioso", em algumas culturas. Iniciamos ali a etapa da roda de conversas, momento no qual explicamos para as crianças que existem vários contos sobre a origem das bonecas e que um deles diz que as bonecas Abayomi são sem marcações no rosto (nariz, boca, olhos) para que possamos reconhecer nelas a multiplicidade do continente africano.

Abrimos a fala para que as alunas e alunos pudessem falar o que acharam da oficina ou perguntassem alguma coisa. Eles demoraram um pouco para perder a timidez e foram encorajados pela professora a dizer o que acharam. A primeira aluna levantou o dedo e disse: "Eu gostei da Abayomi, porque ela parece contigo. Ela é muito bonitinha, igual a você." Outra aluna também se manifestou e disse que gostou da experiência, porque eles mesmos puderam fazer e era fácil. Logo outras alunas falaram que estavam pegando os retalhos que haviam sobrado. Pedimos que elas ajudassem a guardar para que o material pudesse ser usado em outras oficinas, com outras crianças. Nesse momento, observamos as alunas usando os tecidos para fazer caminhas e cobertas para as bonecas Abayomi, ações que crianças costumam reproduzir com as bonecas de mercado.

Os meninos não expressavam desconforto por terem confeccionado uma boneca e alguns deles demonstravam frustração quando achavam que a boneca não era bonita o suficiente. Durante a roda de conversas, muitas meninas ficaram brincando com a boneca Aisha, demonstrando muito cuidado e afeto com o brinquedo. Quando finali- 
zamos, elas se despediram e pediram para dar mais um abraço na boneca. Algumas crianças perguntavam quando retornaríamos e a professora disse que iríamos combinar outro dia. A professora agradeceu e pediu que os alunos também agradecessem não só a nossa presença. Um ponto que nos chamou a atenção, nesta escola, foi o fato de os convites para palestras e oficinas sempre serem direcionados para os alunos e não para o corpo docente. Isso nos faz indagar se o racismo ainda é visto como um problema que diz respeito somente aos alunos sem que atividades semelhantes a essa pudessem ser oferecidas para os professores, funcionários e responsáveis.

As ofıcinas são experimentos que exemplificam uma das estratégias usada pelo movimento negro que têm construído para a manutenção e fortalecimento da etnicidade afro-brasileira. Apesar de ser importante reafirmar a existência do racismo para combatê-lo. É também importante o registro de projetos exitosos. Como o movimento negro é diverso, direcionamos nosso olhar para um grupo específico: as ativistas das redes sociais que desenvolvem oficinas antirracistas em escolas. O espaço virtual é o meio aonde chegam esses convites motivados pela visibilidade que algumas blogueiras ganham no tratamento dado à questão racial. Educadores, que realizam esses convites, consideram essas ativistas capacitadas para tratar à temática. Não é incomum a geração de novos convites de educadores devido às postagens realizadas pela blogueiras nas suas redes sociais. Ressaltamos que este tipo de intervenção (atuação nas escolas) não é utilizado somente por ciberativistas. Outros movimentos sociais utilizam da possibilidade de realizar atividades em espaços escolares. No caso das ativistas negras que executam oficinas em escolas, as ações desenvolvidas em espaços escolares conectam-se as demandas do movimento negro, ou seja, a luta pelo direito à educação e uma educação que valorize o negro e sua cultura. Consideramos que as novas tecnologias da informação e comunicação são elementos importantes para a articulação dos afro-brasileiros no século XXI: inspirando ações que vão 
além do espaço digital, contribuindo para fortalecer este grupo étnico e o protagonismo da juventude negra nas lutas no cenário virtual. A cultura popular negra não é pura, e sim fruto de negociações com a cultura dominante e com as demais culturas, no entanto a escolha de determinados itens culturais assumem significados simbólicos para a construção do grupo e de sua etnicidade. A cultura popular negra é dinâmica e seus itens adquirem múltiplos significados dependendo do contexto em que são acionados. No início da segunda década do século XXI tanto os turbantes quanto as bonecas artesanais adquirem significados para a comunidade negra do Rio de Janeiro e para outras localidades espalhadas em todo território nacional. As blogueiras negras são, em parte, responsáveis por essa difusão. A etnicidade está ligada ao sentimento de pertencimento e se dá em meio à socialização, à transmissão dos seus marcadores, com o intuito de manter as características que configuram o grupo étnico. Por conta da hierarquização das culturas, construída e referenciada em uma visão eurocentrada, as culturas afro-brasileiras se encontram em uma posição de inferioridade na sociedade. Promover atividades que coloquem os afro-brasileiros em uma posição de protagonismo, socializando, positivamente, os símbolos étnicos, são alternativas para garantir oportunidades de ressignificação positiva de suas tradições e manifestações culturais.

A etnicidade é um fenômeno social, não estando relacionado com a natureza. Nascer negro não fará um indivíduo se reconhecer automaticamente como parte do grupo étnico afro-brasileiro. Esse sentimento de pertença é construído por meio de interação com os demais membros do grupo. A fronteira étnica canaliza a vida social, acarretando de um modo frequente uma organização muito complexa das relações sociais e comportamentais. E as oficinas são uma forma de estimular esse sentimento de reconhecimento grupal - de forma de que o indivíduo negro se identifique de maneira positiva com seu grupo étnico - e permite que a escola e a comunidade promovam um intercâmbio de culturas. 
Por foça da lei n 10.639/03, o ensino da história e da cultura afro-brasileira e africana tornou-se obrigatória, no entanto, a temática ainda não foi plenamente implantada nos currículos escolares. É preciso haver mudanças de atitude, desconstruindo diariamente as práticas racistas no ambiente escolar. Os currículos eurocêntricos e as práticas racistas presentes nas relações sociais no âmbito escolar não são levados em conta. Segundo a professora Thalita, falta preparo dos docentes para lidar com as questões relativas ao racismo e, por isso, acabam recorrendo aos ativistas por nos considerarem pessoas mais preparadas para lidar com o assunto. Como o racismo está presente na estrutura da sociedade, é preciso um trabalho permanente para desconstruir as práticas escolares racistas. Mesmo após mais de uma década de implantação da lei n 10.639/03, ainda faltam investimentos em sua implementação e na divulgação de experimentos exitosos. Contribuir com experimentos educativos para o desenvolvimento de educação para as relações étnico-raciais é uma estratégia de luta. As blogueiras negras, a partir de suas experiências pessoais, ingressam no ativismo usando as ferramentas digitais, criando assim, um tipo particular de ação educativa que sai do espaço virtual e chega à escola. Na escola, suas ações são orientadas em direção ao fortalecimento da etnicidade afro-brasileira e da autoestima da criança negra. Assim, quanto mais forte for à etnicidade do grupo mais fortalecido o grupo será para lutar pelas suas demandas de inserção social.

\section{Referências}

ANDRÉ, Marli Eliza D. A. Etnografia da prática escolar. Campinas: Papirus.2005

BARTH, F. “Grupos Étnicos e suas fronteiras”. In: P. POUTIGNAT. Teorias da etnicidade. São Paulo: Ed. UNESP.1976.

BRACA, Aline O. Solta o cabelo!: etnografia sobre o cabelo crespo como marcador de identidade étnico racial entre crianças negras da educação infantil. Dissertação. Rio de Janeiro: UERJ.2006. 
BRASIL. Lei $n^{\circ}$ 9.394, de 20 de dezembro de 1996. Estabelece as diretrizes e bases da educação nacional. Brasília, DF. 1996.

BRASIL. Lei $n^{\circ}$ 10.639, de 9 de janeiro de 2003. Altera a Lei no 9.394, de 20 de dezembro de 1996, que estabelece as diretrizes e bases da educação nacional, para incluir no currículo oficial da Rede de Ensino a obrigatoriedade da temática “História e Cultura Afro-Brasileira", e dá outras providências. Brasília, DF. 2003.

BRASIL. Ministério da Educação. Diretrizes Curriculares Nacionais para a Educação das Relações Étnico-Raciais e para o Ensino de História e Cultura Afro-Brasileira e Africana. Brasília, DF. 2013.

BRASIL. Instituto Brasileiro de Geografia e Estatística (IBCE). 2010. Censo 2010. Rio de Janeiro: IBCE.2010.

BRASIL. Instituto Brasileiro de Geografia e Estatística (IBCE). 2015. Síntese de indicadores sociais: uma análise das condições de vida da população brasileira - 2015. Rio de Janeiro: IBGE, 2015.

CASTELLS, Manuel. Redes de indignação e esperança. Rio de Janeiro: Zahar. 2013. FICUEIREDO, Angela. "Cabelo, cabeleira, cabeluda, descabelada: identidade, consumo e manipulação de aparência entre os negros brasileiros". In: Reunião Anual da Associação Nacional de Pós-Graduação: Pesquisa em Ciências Sociais. 26. Caxambu. 2002.

$\mathrm{COHN}$, Maria da Clória. "Movimentos sociais na contemporaneidade". Revista Brasileira de Educação, 16(47): 333-361. 2011.

GOMES, N. L. "Educação, identidade negra e formação de professores: Um olhar sobre o corpo negro e o cabelo crespo". Educação e Pesquisa, 29(1): 2003.167-182.

GONÇALVES et al. "Movimento negro e educação". Revista Brasileira de Educação, 15: 134-158. 2000.

GONÇALVES, M. A. R."Sobre etnicidade, grupo étnico e cultura afro-brasileira no sistema de ensino brasileiro". In: SISS. A; MONTEIRO. A. (orgs.). Educação e etnicidade: diálogos e ressignificações. Rio de Janeiro: Quartet: Leafro. 2011.

HALL, Stuart."Que negro é esse na cultura negra? In: Da Diáspora. Identidades e mediações culturais. Belo Horizonte: UFMG. 2003.

HOOKS, bell. Alisando o nosso cabelo. Revista Gazeta de Cuba, Unión de Escritores y Artistas de Cuba, jan./fev. 2005 Disponível em: <http://coletivomarias.blogspot.com.br/2008/05/alisando-o-nosso-cabelo.html.. Acesso em: 3 ago. 2014. 
OLIVEIRA, I. "Os 10 anos da lei 10.639/2003 e a educação". Revista Teias 14(34): 191-196. 2013.

PEREIRA, Vinícius Oliveira. 2016. Capoeira e escola: um debate sobre patrimônio, cultura afro-brasileira e educação. Dissertação. Rio de Janeiro: UERJ.

PEREIRA, Bruna de Paula. Ativismo digital e educação: A voz das redes ocupando espaços presenciais.Dissertação. Rio de Janeiro. UERJ. 2016.

PIRES. Heloísa. Histórias da Preta. 1998. São Paulo: Companhia das Letrinhas.1998.

RIFIOTIS, Theophilos. Desafios contemporâneos para a antropologia no ciberespaço: o lugar da técnica. Civitas, Porto Alegre 12(3): 566-578. 2012.

SEYFERTH, Giralda. "A dimensão cultural da imigração". Revista Brasileira de Ciências Sociais, 26(77): 47-62. 2011.

TAFARELLO, Claudia Siqueira César. "Análise crítica entre etnografia e netnografia: métodos de pesquisa empírica". In: $9^{\circ}$ Interprogramas de Mestrado em Comunicação da Faculdade Cásper Líbero. 2014.

WEBER, Max. "Relações Comunitárias Étnicas". In: WEBER, Max. Economia e Sociedade. Brasília: Editora da UNB. v. 1. 1991.

\section{Notas}

1 Organização de Fomento: FAPERJ/Prociência.

2 Secretaria Municipal de Educação de Mesquita/Rj; Mestre em Educação pelo PPCECC da UERJ; docente; Brasil; ORCID: :https://orcid.org/0000-0003-42893284.; e-mail: profbrunadepaulla@hotmail.com

3 Universidade do Estado do Rio de Janeiro; Doutora em Saúde Coletiva pela UERJ; professora associada da Faculdade de Educação e do Programa de Pós-graduação em Educação, Cultura, Comunicação em Periferias Urbanas da UERJ; Brasil; ORCID: :https://orcid.org/0000-0002-6120-554X; e-mail: marialicerezende@ uol.com.br

4 Segundo Rifiotis (2016), o espaço virtual deve ser considerado como um actante nas análises sobre cibercultura.

5 Versão brasileira do The Black Coogler Network, que é um grupo de empregados negros do Coogle, cujo objetivo é recrutar, treinar e desenvolver novos talentos negros para a empresa. 
6 Disponivel em: http://www.theblackcupcake.com/2015/11/quando-alma-encontra-o-corpo.html

7 Como são conhecidos na rede os indivíduos que possuem canal no YouTube.

8 Nome fictício para manter o anonimato da escola pesquisada.

9 Nome fictício para manter em sigilo do nome real da instituição.

10 Números coletados em 2015, disponíveis em: http://cidades.ibge.gov.br/xtras/ grafico_cidades. php?lang $=\&$ codmun $=330285 \&$ idtema $=156 \&$ search $=$ rio - de - ja neirolmesquitalensino-matriculas-docentes-e-rede-escolar-2015. Acesso em: 20 maio 2020.

11 Os nomes da escola e das pessoas envolvidas na pesquisa foram modificados para resguardar a identidade dos envolvidos.

12 O livro apresenta a história e cultura afro-brasileira reunindo contos narrados pela personagem principal, Preta.

13 Um dos vídeos está disponível em: https://www.youtube.com/watch?v=CdoqqmNB9JE. Acesso em: 26 maio 2020.

14 http://www.artedobrasil.com.br/valdilena_serra.html. Acesso em 29 de agosto de 2020.

15 Mais informações em: https://extra.globo.com/noticias/primeira-loja-dedicada-bonecas-negras-do-brasil-sera-aberta-no-rio-23452839.html. Acesso em: 26 maio 2020.

16 Disponível em: https://eraumavezomundo.com.br/. Acesso em: 28 maio 2020. 


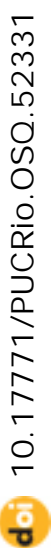

